\title{
VARIATIONS IN THE ANGLE OF ANOMALY AND FUSIONAL MOVEMENTS IN CASES OF SMALL-ANGLE CONVERGENT STRABISMUS WITH HARMONIOUS ANOMALOUS RETINAL CORRESPONDENCE*
}

\author{
BY \\ G. MARAINI AND L. PASINO \\ Clinica Oculistica, University of Parma, Italy (Director, Professor P. Matteucci)
}

IT is generally accepted that nearly all patients with fixed small-angle convergent strabismus and bilateral central fixation show harmonious anomalous retinal correspondence (h.a.r.c.) when examined in normal surroundings under nondissociating test conditions (Bagolini's striated glasses) (Bagolini and Tittarelli, 1960; Pasino and Maraini, 1962). H.a.r.c. has been shown to adapt itself quite easily to small variations in the angle of deviation (Pasino and Maraini, 1964), which suggests the possible existence of a certain fusional amplitude in these subjects. The possibility of variation in the angle of anomaly has already been admitted by some authors (Burian, 1958; Hallden, 1952; Kretzschmar, 1955) as a rare phenomenon, and Swan (1948) reported an adaptation of the angle of anomaly to the angle of deviation. Our experience leads us to think that, by using the least amount of dissociation, this is the rule rather than the exception.

These variations in the angle of anomaly could alone account for a certain "fusional amplitude" of practical value in these subjects; but while some authors claim that real fusional movements can be elicited in such patients (Burian, 1941; Hallden, 1952; Lyle, 1962), others could not confirm these findings (Kretschmar, 1955). Burian's investigations by polarized haploscopy do not exclude variations in the angle of anomaly (since the position of the eye was not registered during the testing), and Hallden tested the subjective angle not with fusional targets but with simultaneous vision targets; it may therefore be difficult to claim fusional movements in the absence of clearly demonstrated fusion. On the contrary, according to Kretschmar's investigations, which show the ready variation of the angle of anomaly following the position of haploscopic fusion targets, real fusional movements seem to be exceedingly rare in these patients.

Both theoretically and practically this problem is important and should be studied only under natural test conditions approaching those of everyday life, and excluding all artificial and dissociating factors. We have therefore investigated, in cases of small-angle convergent strabismus, the real fusional movements or variations in the angle of anomaly which may follow the introduction of a horizontal disparity.

\section{Method}

A subject with small-angle convergent strabismus, bilateral foveal fixation, and h.a.r.c. in normal surroundings, is placed in front of a uniformly illuminated white screen with a central luminous fixation point. While the patient fixes the fixation point with the dominant eye, the image in the deviating eye will fall on a point in the retina eccentric and nasal 
to the fovea (Point 0 ). By means of striated glasses, the same straight-ahead direction of the two stimulated retinal points (fovea of the dominant eye and Point $\mathrm{O}$ of the deviating eye) and the resulting fusion in anomalous binocular vision (a.b.v.) may easily be demonstrated. After a cross-like foveal after-image has been elicited in the deviating eye by means of an electronic flash, the subject is usually able, while steadily fixing the central fixation point and maintaining a.b.v., to recognize and locate the after-image with the aid of an intermittent illumination of the screen. Since we are dealing with convergence, the after-image will be located on the side of the fixing eye and the distance between its centre and the fixation point will indicate the distance between the fovea and Point $O$, i.e. the angle of anomaly (or the angle of deviation since the subject has h.a.r.c.) (Fig. 1 and Fig. 2A).
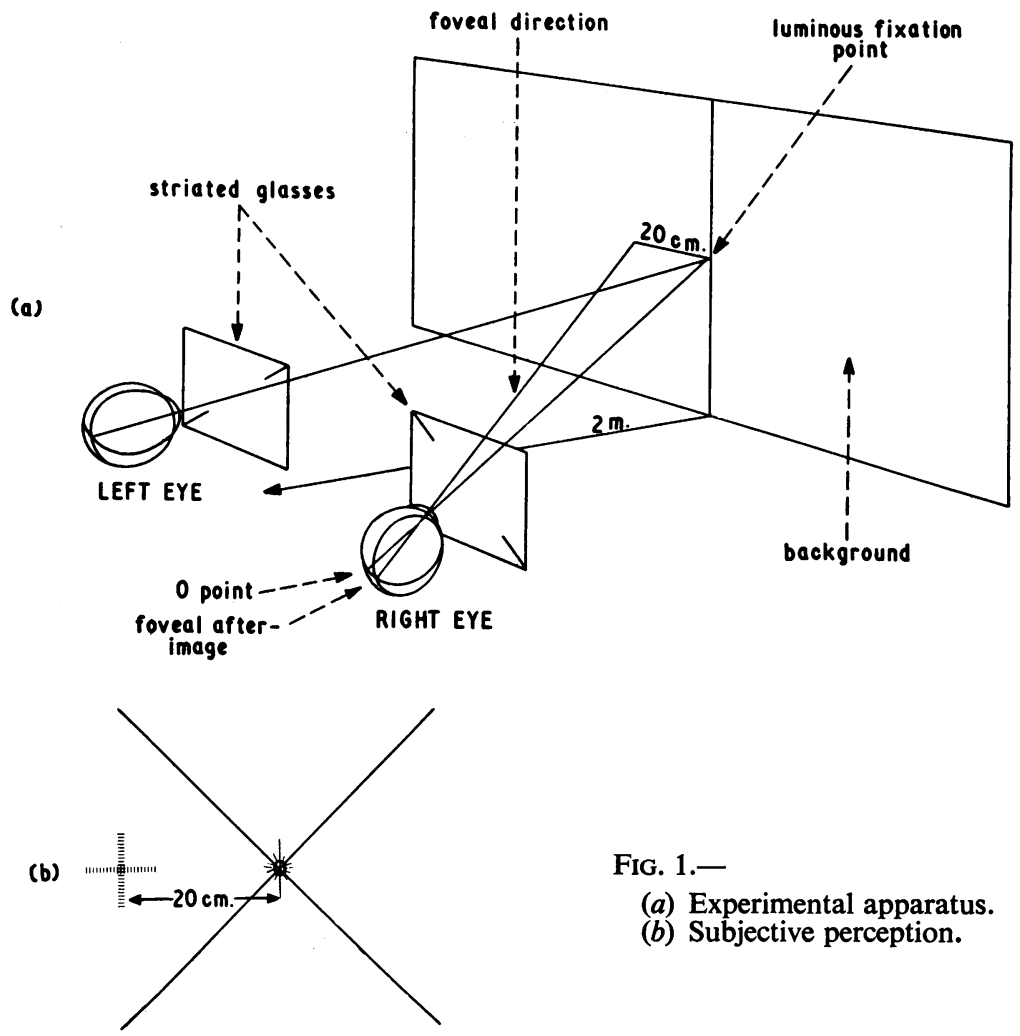

Fig. 1.-

(a) Experimental apparatus.

(b) Subjective perception.

If a prismatic lens of $6 \Delta$ base out is now placed before the deviating eye, the stimulated retinal points will change, and will become more temporal than the previous Point $O$.

All the subjects examined maintained h.a.r.c. even after the introduction of the prism. Change in the angle of anomaly may be differentiated from fusional movement in the following way:

\section{(1) Variation of the Angle of Anomaly (Fig. 2B)}

After the introduction of a $6 \Delta$ prism base out, while the subject maintains a.b.v., a different retinal point will take up the straight-ahead localization in the deviating eye. The eccentricity of Point $O$ will be altered and the after-image will be located by the subject 
A

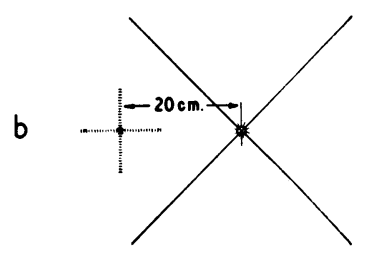

0

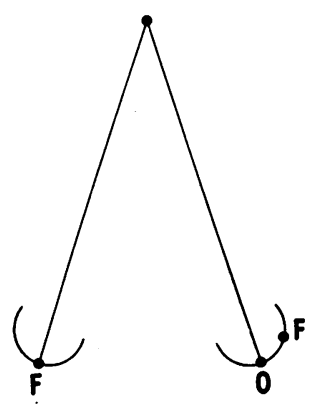

$B$
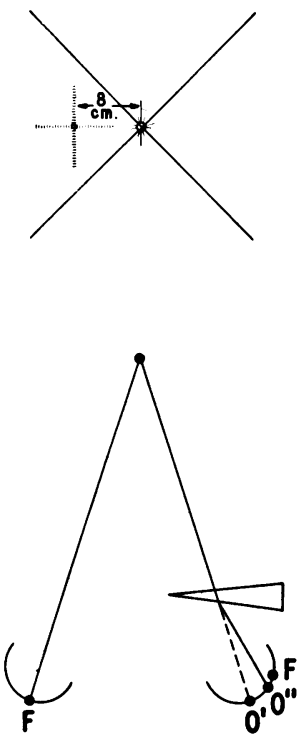

C
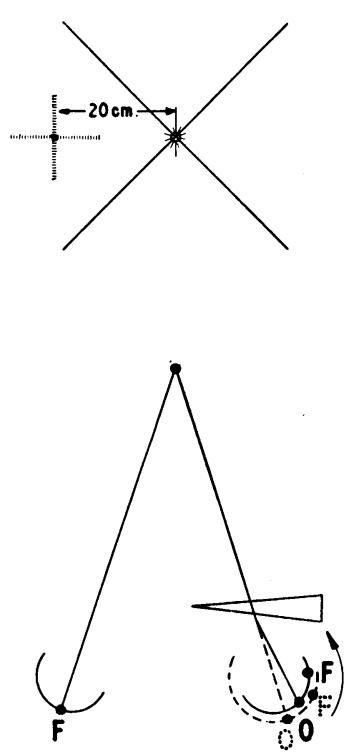

FIG. 2.-

A. Diagram of the change after introduction of a prism.

B. Subjective perception.

C. Fusional movement.

nearer to the fixation point (the after-image shift will theoretically correspond to the power of the prism for a given distance of the subject from the fixation point).

(2) Fusional Movement (Fig. 2c)

After the introduction of the prism, a.b.v. will be maintained by an eye movement that will bring the image of the fixation point back to the previously stimulated Point $O$. The eccentricity of Point $O$ will not vary; the distance between the fovea and Point $O$ will not change and no modification of the distance between the after-image and the fixation point will be noticed by the subject.

\section{Material}

Eleven patients ranging in age from 9 to 27 years, were examined. All had small-angle convergent strabismus (not less that $6^{\Delta}$ at $2 \mathrm{~m}$.), foveal fixation in both eyes, and h.a.r.c in normal surroundings. After the introduction of a $6 \Delta$ prism base out in front of the squinting eye, they all retained h.a.r.c. either immediately or after a few seconds. Each subject was examined on at least two different days, several tests being performed on each occasion. Because of the complexity of the subjective observations required, we have included only those patients who behaved in exactly the same way during all the different tests.

\section{Results}

These are set out in the Table (overleaf).

In Cases 2, 3, 4, and 5, a.b.v. is clearly maintained exclusively by varying the angle of anomaly. In these cases the after-image displacement corresponds exactly to the displacement of Point $\mathrm{O}$, which would be expected according to the power of the prism. 
TABLE

RESULTS IN ELEVEN CASES

\begin{tabular}{|c|c|c|c|c|c|c|}
\hline $\begin{array}{l}\text { Case } \\
\text { No. }\end{array}$ & Sex & $\begin{array}{l}\text { Age } \\
\text { (yrs) }\end{array}$ & Esotropia & $\underset{\text { Eye }}{\text { Dominant }}$ & $\begin{array}{l}\text { Location of } \\
\text { Foveal After-Image } \\
\text { in Deviating Eye }\end{array}$ & $\begin{array}{c}\text { Location of After- } \\
\text { Image after Introduc- } \\
\text { tion of } 6 \Delta \text { Prism Base } \\
\text { Out }\end{array}$ \\
\hline 1 & $\mathbf{F}$ & 9 & Alternating $+8 \Delta$ at $5 \mathrm{~m}$ & $\mathbf{L}$ & $15 \mathrm{~cm}$. to left & $9 \mathrm{~cm}$. to left \\
\hline 2 & $\mathbf{M}$ & 13 & Alternating $+8 \Delta$ at $5 \mathrm{~m}$. & $\mathbf{R}$ & $22 \mathrm{~cm}$. to right & $11 \mathrm{~cm}$. to right \\
\hline 3 & $\mathbf{M}$ & 27 & Alternating $+15 \Delta$ at $5 \mathrm{~m}$. & $\mathbf{L}$ & $50 \mathrm{~cm}$. to left & $35 \mathrm{~cm}$. to left \\
\hline 4 & $\mathbf{F}$ & 13 & Alternating $+10 \Delta$ at $5 \mathrm{~m}$ & $\mathbf{R}$ & $26 \mathrm{~cm}$. to right & $13 \mathrm{~cm}$. to right \\
\hline 5 & $\mathbf{F}$ & 12 & Right $+10 \Delta$ at $5 \mathrm{~m}$. & $\mathrm{L}$ & $21 \mathrm{~cm}$. to left & $12 \mathrm{~cm}$. to left \\
\hline 6 & $\mathbf{M}$ & 16 & Left $+8 \Delta$ at $5 \mathrm{~m}$ & $\mathbf{R}$ & $10 \mathrm{~cm}$. to right & $5 \mathrm{~cm}$. to right* \\
\hline 7 & $\mathbf{F}$ & 9 & Alternating $+6 \Delta$ at $5 \mathrm{~m}$. & $\mathbf{R}$ & $7 \mathrm{~cm}$. to right & $\begin{array}{l}\text { Almost on Fixation } \\
\text { point }\end{array}$ \\
\hline 8 & $\mathbf{M}$ & 9 & Alternating $+6 \Delta$ at $5 \mathrm{~m}$. & $\mathbf{R}$ & $16 \mathrm{~cm}$. to right & $\begin{array}{l}16 \mathrm{~cm} \text {. to right } \\
\text { (no change) }\end{array}$ \\
\hline 9 & $\mathbf{F}$ & 14 & Right $+8 \triangle$ at $5 \mathrm{~m}$ & $\mathbf{L}$ & $12 \mathrm{~cm}$. to left & $\begin{array}{l}12 \mathrm{~cm} \text {. to left } \\
\text { (no change) } \dagger\end{array}$ \\
\hline 10 & $\mathbf{F}$ & 10 & Left $+8 \Delta$ at $5 \mathrm{~m}$. & $\mathbf{R}$ & $32 \mathrm{~cm}$. to right & $\begin{array}{l}32 \mathrm{~cm} \text {. to left } \\
\text { (no change) } \dagger\end{array}$ \\
\hline 11 & $\mathbf{M}$ & 26 & Right $+8 \Delta$ at $5 \mathrm{~m}$. & $\mathbf{L}$ & $15 \mathrm{~cm}$. to left & $9 \mathrm{~cm}$. to left \\
\hline
\end{tabular}

* In Case 6, after the introduction of the prism, an unharmonious retinal correspondence was observed for a few moments, and was rapidly followed by restoration of a.b.v. and displacement of the after-image.

$\dagger$ In Cases 9 and 10 after the introduction of the prism, transient diplopia was rapidly followed by restoration of a.b.v. without displacement of the after-image.

In Cases 1, 6, 7, and 11, the after-image displacement is less than expected. In such cases one may postulate the association of a variation in the angle of anomaly and an incomplete fusional movement.

In Cases 8, 9, and 10, there was no displacement of the after-image, indicating that a.b.v. is maintained by an eye movement of the fusional type that leaves the distance between the fovea and Point $O$ unchanged. In two of these patients (Cases 9 and 10), a.b.v. was maintained after a transient diplopia analogous to that which occurs in a normal subject in these experimental conditions.

\section{Discussion}

The data demonstrate how readily the angle of anomaly may vary in patients with h.a.r.c. and small-angle convergent strabismus. Real fusional movements are also shown to be possible, but occur much less frequently. A variation in the angle of anomaly and a fusional movement may also occur together.

It might be of interest to study the influence on these processes of previous surgical and orthoptic treatment. 


\section{Summary}

The occurrence of real fusional movements in normal surroundings has been recorded in patients with small-angle convergent strabismus and harmonious anomalous retinal correspondence, but this phenomenon was infrequent in comparison with variations in the angle of anomaly.

\section{REFERENCES}

Bagolini, B., and Tittarelli, R. (1960). Boll. Ocul., 39, 211.

BURIAN, H. M. (1941). Arch. Ophthal. (Chicago), 26, 626.

(1958) "Normal and Anomalous Correspondence", in "Strabismus Ophthalmic Symposium, II", ed. J. H. Allen. Mosby, St. Louis.

HALLDEN, U. (1952). Acta ophthal. (Kbh.), Suppl. 37.

KRETSChMAR, S. (1955). Docum. Ophthal., 9, 46.

LYLE, T. KeITH (1962). Personal communication.

Pasino, L., and MarainI, G. (1962). Rass. ital. Ottal., 31, 92.

(1964). Brit. J. Ophthal., 48, 30.

Swan, K. C. (1948). Arch. Ophthal. (Chicago), 40, 371. 